\title{
Newer Innovations in Treatment of Retracted Nipple: Authors' Reply
}

\author{
Suchitra Jain • Anand Jain • Amit K. Singh • \\ Divya Goswami • Amar N. Upadhyay • Neha Negi
}

Received: 15 April 2013 / Accepted: 16 April 2013 /Published online: 25 July 2013

(C) Dr. K C Chaudhuri Foundation 2013

To the Editor: We are really thankful to Dr T. Arun Babu and Dr Patra for their interest shown in our study [1].

Regarding the gestational age at which it was started as mentioned clearly (Material and Methods, line 1), it was applied post natally and not during gestation. Otherwise also, during gestation it is never advised for fear of inducing uterine contractions and/or premature labour.

Regarding the frequency and duration of intervention, it has been mentioned (Material and Methods, line 9-11) that sucking was done till nipple became protruded, at least for the time being, to enable sucking by the baby. It was every time before putting the baby at breast (frequency). Once it was successful i.e., on day 3 in $52 \%$, day 7 in $88 \%$ and day 14 in $94 \%$, it was no more required and duration is self explanatory.

On initial days after parturition, no husband is going to suck at nipple as a foreplay and since the groups A and B were not advised for sucking at nipple by husbands as a medical intervention, its chances are zero/negligible. Thus, the groups are truly comparable.

S. Jain · D. Goswami

Department of Gynaecology, VCSGGMS\&RI, Govt. Medical,

College, Srinagar Garhwal, Uttarakhand, India

A. Jain $\cdot$ A. N. Upadhyay $\cdot$ N. Negi

Department of Pediatrics, VCSGGMS\&RI, Government Medical

College, Srinagar Garhwal, Uttarakhand, India

A. K. Singh

Department of Pediatrics, Government Medical College,

Haldwani, Uttarakhand, India

\section{A. Jain $(\square)$}

Department of Pediatrics, 25, New Resident Hostel, H.N.B., Base

Hospital, Srinagar Garhwal, Distt,

Pauri Garhwal, Uttarakhand 246 174, India

e-mail: drjain_anand@yahoo.com
Chances of transmitting infection to the newborn are very little, still husbands can be asked to gargle with plain water/antiseptic gargles before sucking. A little advantage of salivary Ig A benefit is also there.

For times immortal, sucking has been a part of foreplay, never resulting in trauma to the nipple, since the act is very delicate and both the participants are intimately attached to each other mentally. It is the excess negative pressure responsible for trauma but here the negative pressure (i.e., sucking force) was immediately reduced, on expression of pain, (unlike in syringe method) and practically trauma was never seen. Still, the risk if any, far outweighs the benefits.

We have already accepted that societies where it is not acceptable, it should not be advised. Still, looking at immense benefits of the procedure (already mentioned), we did intensive efforts on counselling, satisfying all the queries of the patients. We stressed that there is nothing wrong in it and huge benefits, counselled both the participants singly and then together. We feel that with full hearted and laborious efforts we got $79.7 \%$ acceptability. Questionnaire method as applied by Babu et al., perhaps lacked personal touch and prevented the most valuable whole hearted and sternous personal efforts in singly and then in together counselling, resulting in $13.2 \%$ acceptability.

Although, we hope this satisfies all the queries raised by the learned doctors, we fully agree, that this new and unique method needs further trials, as already mentioned by us.

\section{Reference}

1. Jain S, Jain A, Singh AK, Goswami D, Upadhyay AN, Negi N. Newer innovations in treatment of retracted nipple. Indian J Pediatr. 2012; doi:10.1007s12098-012-0833-9. 